\title{
Formulation and investigation of turmeric extract and sodium benzoate loaded capsules
}

\author{
ILDIKÓ BÁCSKAY1,2,3, DÁVID SINKA' ${ }^{1,2,3}$, LIZA JÓZSA ${ }^{1,2,3}$, GÁBOR VASAS²,4, ZOLTÁN UJHELYI ${ }^{1,2,3}$, \\ PÁLMA FEHÉR ${ }^{1,2,3}{ }^{*}$, BÉLA JUHÁSZ ${ }^{5}$, ZOLTÁN SZILVÁSSY ${ }^{5}$
}

\author{
${ }^{1}$ Department of Pharmaceutical Technology, University of Debrecen, Nagyerdei körút 98, 4032 Debrecen, Hungary \\ ${ }^{2}$ Doctoral School of Pharmaceutical Sciences, University of Debrecen, Nagyerdei körút 98, 4032 Debrecen, Hungary \\ ${ }^{3}$ Institute of Healthcare Industry, University of Debrecen, Nagyerdei Körút 98, 4032 Debrecen, Hungary \\ ${ }^{4}$ Department of Pharmacognosy, University of Debrecen, Nagyerdei körút 98, 4032 Debrecen, Hungary \\ ${ }^{5}$ Department of Pharmacology and Pharmacotherapy, University of Debrecen, \\ Nagyerdei körút 98, 4032 Debrecen, Hungary. \\ * Corresponding author: Pálma Fehér \\ Email:feher.palma@pharm.unideb.hu
}

Received: 7 January 2021 / Revised: 16 February 2021 / Accepted: 16 February 2021

\begin{abstract}
Turmeric has been studied and used as a plant derivate active ingredient for centuries. Several effects of turmeric have been described, however the poor solubility of its active ingredients during the formulation development may limit oral applicability. The aim of research was to involve the development of a dietary supplement of a hard capsule containing turmeric (Curcuma longa) (ground powder from the root standardized to curcuminoid content) and sodium benzoate. The manufacturing technology and the analytic method of the formulation have been developed. Formulation studies according to the Ph. Hg. VIII. standards have been performed. The product may have insulin sensitizing and memory enhancing effects, related animal studies are ongoing.
\end{abstract}

Keywords: Curcuma longa, Turmeric, Curcumin, Sodium benzoate, HPMC capsule

\section{Introduction}

Nowadays, herbal medicines are playing an increasingly important role in maintaining the health of the world's population. At least 80 percent of patients have already been treated with natural agents, according to a World Health Organization (WHO) survey [1]. Members of the genus Curcuma longa have been used in medicine for centuries due to its complex composition and its beneficial effects for the human health [2].

Curcuma longa (C. longa), commonly known as turmeric, is a rhizomatous herbaceous plant of the ginger family (Zingiberaceae) [3], which is cultivated excessively in India for medicinal and also culinary purposes [4]. The most important components of $C$. longa are phenylpropanoid derivatives called curcuminoids, a group whose main representatives are curcumin (diferuloylmethane), demethoxycurcumin, and bis-demethoxycurcumin [5]. The plant is also rich in sesquiterpene volatile components [6].

The most extensively studied compound derived from C. longa is the curcumin which is a low molecular-weight polyphenol, with the molecular formula of $\mathrm{C}_{21} \mathrm{H}_{20} \mathrm{O}_{6}$ [7]. Curcumin has a variety of beneficial biological and pharmacological activities. Numerous publications report the effects of curcumin on human health, it has low toxicity with promising clinical application. It has antioxidant, anti-inflammatory, neuroprotective, hypoglycemic, anti-tumor, hepatoprotective, and cardioprotective effects; and can be used in the therapy of allergic rhinitis, depression, hyperlipidaemia, non-alcoholic fatty liver disease, osteoarthritis, uraemic pruritus and colitis ulcerosa as well [812]. Curcumin also shows antihyperglycemic and insulin sensitizer effects as it can reduce blood glucose level by reducing the hepatic glucose production and stimulating glucose uptake by the upregulation of the gene expression of various glucose transporters (GLUTs). According to the literature, curcumin may affect GLUT4, GLUT2 and GLUT3 gene expression $[13,14]$. Some promising effects have been observed in patients with dementia which could indicate the memory enhancing property of Curcuma longa [15].

The effect mechanisms of curcumin were examined via in vitro studies, animal models and human studies, and mostly curcuminoids were found responsible for the effects $[13,14,16]$. It has been determined that the curcumin exerts its anti-inflammato- 
ry effect by inhibiting the nuclear factor $\kappa \mathrm{B}(\mathrm{NF}-\kappa \mathrm{B})$ and tumor necrosis factor (TNF) $-\alpha$ expression, as well as impairing lipopolysaccharide (LPS) signal transmission. In addition, curcumin acts on other signal transmission pathways, such as the peroxisome proliferator-activated gamma receptor (PPAR- $\gamma$ ) and the Toll-like receptor- 4 of the myeloid differentiation protein (TLR4-MD2) [17-19].

The therapeutic effects of Curcuma longa are also associated with its antioxidant property. Oxidative damages mediated by free radicals may lead to cell aging and the development of various chronic disorders such as cancer and atherosclerosis. Curcuminoids are able to exert antioxidant effect due to their chemical structure which allows them to scavenge various reactive oxygen species produced by macrophages including superoxide anions, hydrogen peroxide and nitrite radicals [20]. Curcumin is also used in the food industry as a natural food colouring agent because of its orange-yellow colour [8]. Although most of the studies focus only on the beneficial effect of curcumin, other curcuminoid components also have biological activities.

Using the turmeric orally in medicinal dose is well-tolerable and safe; the incidence of adverse effects is low and comparable with the placebo control [21-23]. The most abundant side effects were gastrointestinal upsets, like obstipation, dyspepsia, diarrhea, abdominal pain, reflux and nausea [24]. However, the use of curcumin in medicinal doses should be avoided during pregnancy because of potential uterus stimulating effects. Studies subjecting benefits of Curcuma longa in pregnancy and pregnancy-related complications are almost exclusively based on in vitro or animal model results [25].

The poor solubility of the active ingredients in turmeric may limit oral applicability. During the formulation of a dosage form containing natural active ingredient the main problem is that the biologically active components of natural substances, in addition to their poor water solubility, often poorly penetrate biological membranes and therefore have low absorption, resulting in low bioavailability and effect. The bioavailability of an active ingredient may also be affected by its physicochemical properties, chemical structure, the ratio of hydrophilic to lipophilic groups, and release from the dosage form, properties of the carrier, mode and duration of administration.

The main objective of the present study was the formulation and investigation of a dietary supplement containing Curcuma longa with appropriate bioavailability. Hydroxypropyl methylcellulose (HPMC) capsules were filled with ground turmeric root standardized to curcuminoid content combined with sodium benzoate as active ingredients. Sodium benzoate is a D-amino acid oxidase (DAO) inhibitor [26]. DAO is an enzyme responsible for the catabolism of biogenic amines in the gastrointestinal tract [27]. The inhibition of DAO is a new avenue in the treatment of schizophrenia [28]. According to the literature sodium benzoate can also inhibit reactive oxygen species, thus it has an antioxidant effect [29]. Curcumin combined with sodium benzoate can protect intestinal mucosal barrier function [30], and suppress $\mathrm{T}$ helper type 1 (Th1) immune response, which can be beneficial in inflammatory conditions [31].

Magnesium stearate and anhydrous colloidal silica (Silica colloidalis anhydrica, Aerosil) were also used as excipients in the formulation to improve flow properties of the powder. Mixing magnesium stearate with other particles it coats their surface and acts as lubricant. Lubricants inhibit adhesion to the metallic machine parts and facilitate adequate flow of the formulation. Colloidal silica also has the ability to adhere to the surface of other particles, thus improving flow properties of the blend [32].

Sieve and rheological analysis were conducted with the ground turmeric and with the final blend and the homogeneity was also examined. The analysis of curcuminoids and sodium benzoate was carried out by Liquid Chromatography Electrospray Ionization Tandem Mass Spectrometric (LC-ESI-MS/MS) equipment. Accelerated stability study was also conducted with 20 turmeric capsules form three different manufacturing batches.

\section{Materials and Methods}

\subsection{Materials}

Ground turmeric was obtained from Klenk $\mathrm{GmbH}$ (Germany). Sodium benzoate, silica colloidalis anhydrica and magnesium stearate were purchased from Molar Chemicals (Hungary). Hydroxypropyl methylcellulose (HPMC) capsules were obtained from Capsugel Inc. Reagents for the extraction and analytical part of the study were at least of analytical purity. Methanol and acetonitrile were purchased from Sigma Aldrich (St. Louis, MO, USA). Type I (18.2 $\left.\mathrm{M} \Omega \mathrm{cm}^{-1}\right)$ water purified by a Human Zeneer Power I water purification system 
Table I The parameters of the grinding process with ZM200 Ultra-Centrifigal Mill

\begin{tabular}{l|l}
\hline Rotor of Stainless Steel with Wear-Resistant Coating & 1.4460 \\
\hline Designation & X3CrNiMoN27-5-2 \\
\hline Hardness & $\leq 260 \mathrm{HB}$ \\
\hline Tensile strength & $620-880 \mathrm{~N} / \mathrm{mm}^{2}$ \\
\hline Density & $7.8 \mathrm{~g} / \mathrm{cm}^{3}$ \\
\hline Diameter minimum & $\sim 0.5 \mathrm{~mm}$ \\
\hline Diameter maximum (upon material elasticity) & $\sim 1.0 \mathrm{~mm}$ \\
\hline Average diameter (75-80\%) & $\sim 0.5 \mathrm{~mm}$ \\
\hline RPM & 16000 \\
\hline Power $(\%)$ & $0-65$ \\
\hline Temperature $\left({ }^{\circ} \mathrm{C}\right)$ & $12-31$ \\
\hline
\end{tabular}

(Human corporation, Seoul, South Korea) was used throughout the study.

\subsection{Operation of grinding turmeric powder}

In order to achieve smaller particle size and the homogeneity of mixing the first step was the grinding of turmeric powder. Grinding process was carried out with a RETSCH ZM 200 ultra-centrifugal mill, combined with temperature control. The parameters of the process are presented in Table I; the temperature values are shown on Figure 1. Temperature is one of the most important measurement parameters that is used for monitoring and control in industries. The temperature of powder during the grinding process may cause stability problems therefore it was monitored under the course with a thermometer fixed at the ultra-centrifugal mill [33].

\subsection{Sieve analysis of turmeric ground powder}

Powder sieve analysis is a testing method designed to separate powder based on particle size. It is a beneficial examination that gives crucial information about the properties of the powder [34]. The particle size distribution of the ground turmeric was examined via manual with standard test sieves according to the Pharmacopoeia Hungarica VII. (Ph. Hg. VII.) [35]. Thirty g of ground turmeric powder was sieved for 5 minutes and the mass of powder retained and passed in each sieve was weighted. For determination of particle-size distribution the retained mass of powders on the sieves were measured and expressed as percentage values.

\subsection{Rheological properties of ground turmeric powder}

The flowability of powder affects its behaviour mainly during the filling process. Among other parameters, moisture content, morphology and Particle Size Distribution can all influence flow [36]. In order to test the flowability of ground turmeric powder standard ASTM equipment was used according to the Ph. Eur. $10^{\text {th }}$ Edition. The standard funnel was fixed $40 \mathrm{~mm}$ above the bench surface where a piece of millimetre paper was placed. Fifty $g$ of turmeric powder was measured and poured into the funnel without any trapping, vibration or movement of the funnel while it was blocked with dry finger. The powder was let to flow free and compose a repose on the millimetre paper. The angle of repose for the powder was determined from the cone height $(\mathrm{h})$ in $\mathrm{cm}$ and the radius $(\mathrm{r})$ of the cone base in $\mathrm{cm}$. The angle of repose was calculated as follows:

$$
\theta=\tan ^{-1}(\mathrm{~h} / \mathrm{r})
$$

Carr (1965) developed Carr's index and classified powders according to their flowability using the angle of repose, as indicated in Table II [37].

\subsection{Formulation of final blend}

The composition of the final blend can be seen in Table III. Sodium benzoate was pulverized in a mortar. Silica colloidalis anhydrica and Magnesium stearate were weighted and blended to Erweka Cube Mixer KB 20 and mixed for $10 \mathrm{~min}$ at 220 RPM rotational speed. Sodium benzoate was homogenized with the excipients and finally ground turmeric powder was added in portions to the formulation. The composition was mixed in an Erweka Cube Mixer KB 20 equipment for 10 minutes at 220 RPM rotational speed. 


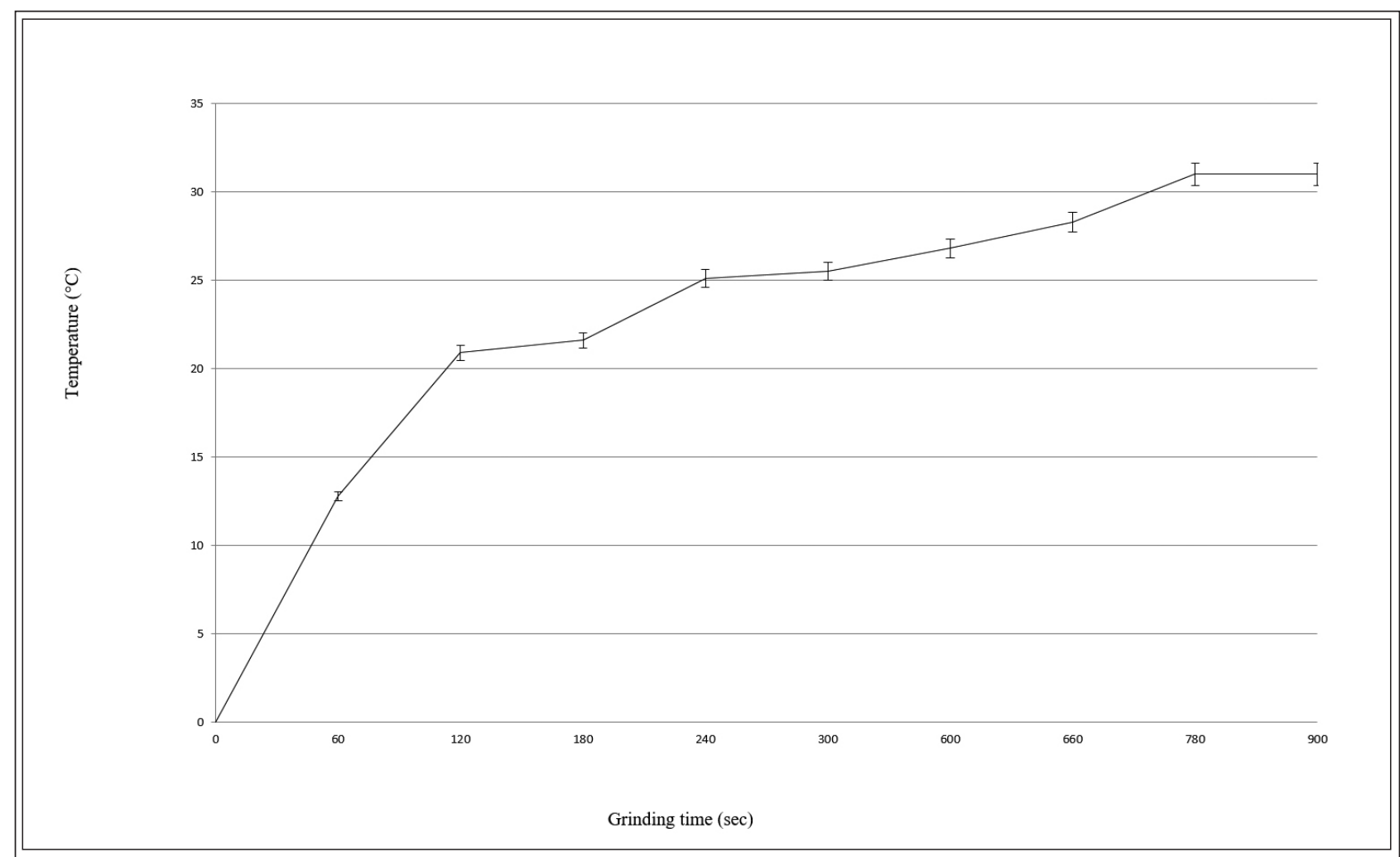

Figure 1 Temperature values during the course of grinding process

Table II The relationship between angle of repose and flowability.

\begin{tabular}{c|c}
\hline Flow property & Angle of repose $(\boldsymbol{\theta})$ \\
\hline Excellent & $25-30$ \\
\hline Good & $31-35$ \\
\hline Fair-aid not needed & $36-40$ \\
\hline Passable-may hang up & $41-45$ \\
\hline Poor-must agitate, vibrate & $46-55$ \\
\hline Very poor & $56-65$ \\
\hline Extremely poor & $>66$ \\
\hline
\end{tabular}

\subsection{Sieve analysis of the final blend}

The particle size distribution of the final blend was examined via manual sieving. $30 \mathrm{~g}$ of final composition was sieved for 5 minutes with standard test sieves of Pharmacopoeia Hungarica VII. (Ph. Hg. VII.) [35]. The mass of powder retained and passed in each sieve was weighted. For determination of particle-size distribution the retained mass of powders on the sieves were measured and expressed as percentage values.

\subsection{Rheological properties of the final blend}

In order to test the flowability of final blend standard ASTM equipment was used according to the European Pharmacopoeia $10^{\text {th }}$ Edition (Ph.
Eur. 10) [38]. The standard funnel was fixed 40 $\mathrm{mm}$ above the bench surface where a piece of millimetre paper was placed. Fifty $g$ of final blend was measured and poured into the funnel without any trapping, vibration or movement of the funnel while it was blocked with dry finger. The powder was let to flow free and compose a repose on the millimetre paper. The angle of repose form the powder was determined from the cone height $(\mathrm{h})$ in $\mathrm{cm}$ and the radius $(\mathrm{r})$ of the cone base in $\mathrm{cm}$.

\subsection{Homogeneity of the final blend}

Purposely to evaluate the effect of mixing on the homogeneity of final blend samples were taken from the Erweka Cube Mixer KB 20 at 5,10,15 min- 
Table III Composition of the final blend

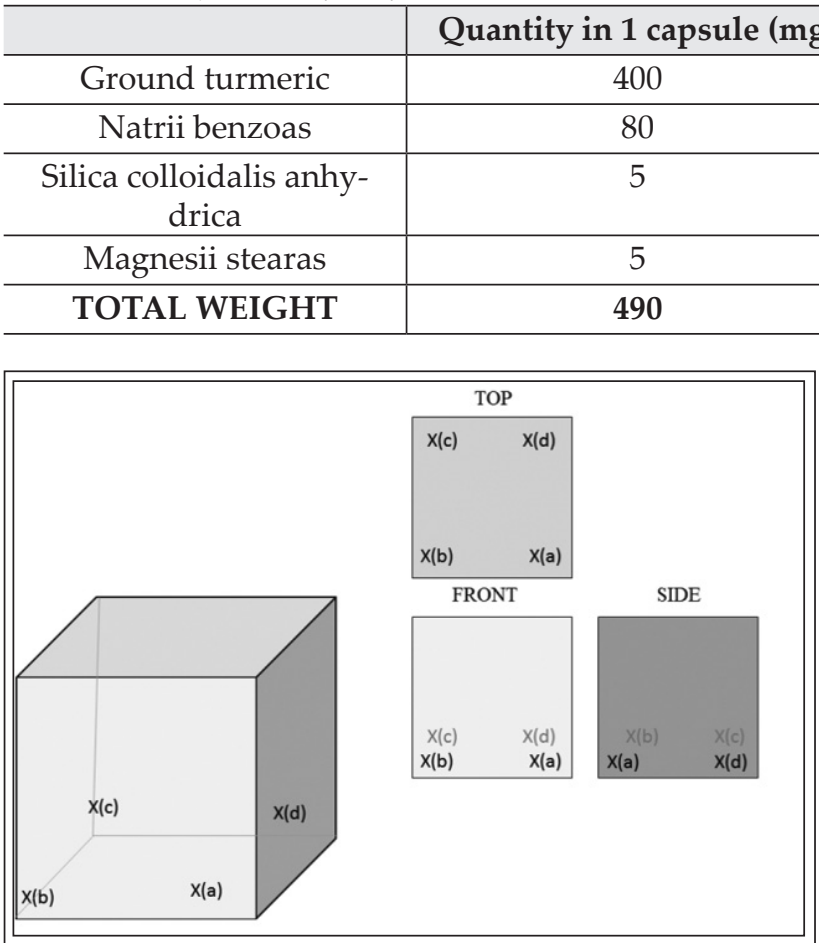

Figure 2 Samples taken from the cubic mixer

utes during the mixing process with a special powder sampler device according to the pattern shown in Figure 2. The quantity of active pharmaceutical ingredients was determined using LC-MS analysis.

\subsection{Extraction and analytical method of curcuminoids}

Curcuminoids (curcumin, demethoxycurcumin and bis-demethoxycurcumin) were detected in native form. Twenty five $\mathrm{mg}$ of final blend or capsule filling was extracted with $1.0 \mathrm{ml}$ methanol (60 minutes, $75^{\circ} \mathrm{C}$ ), centrifuged for 1 minute on 13000 RPM, and the supernatant was diluted 250-fold. One $\mu$ l of the sample solution was injected into LC-ESI-MS/MS equipment (Thermo ACCELA 600 + Thermo LTQ XL), and was studied in water/acetonitrile gradient elution on YMC Triart C18 (100 $\mathrm{mm} \times 3 \mathrm{~mm} \times 1.9 \mu \mathrm{m})$ column. Chromatographic gradient: A: bidestillated water $+0.1 \% \mathrm{HCOOH}, \mathrm{B}$ : $\mathrm{MeCN}+0.1 \% \mathrm{HCOOH} ; 0$ min: $30 \%$ B; $0.1 \mathrm{~min}:$ 30\% B; 10 min: 100\% B; 18 min: 100\%; $16.10 \mathrm{~min}$, 30\%; 18 min: 30\%. ESI parameters: ion source 180 ${ }^{\circ} \mathrm{C},+5 \mathrm{kV}, 100 \mu \mathrm{A}$; capillar $275{ }^{\circ} \mathrm{C},+48 \mathrm{kV}$; gas flow $18 \mathrm{arb}$, secondary gas flow 8 arb. Detection: Isolation width: $1 \mathrm{~m} / \mathrm{z}, 100-600 \mathrm{~m} / \mathrm{z}$ range. $[\mathrm{M}+\mathrm{H}]^{+}$ions were measured in full MS scan: curcumin 369, demethoxycurcumin 339 and bis-demethoxycurcumin 309.

\begin{tabular}{|c|c}
\hline Function & Percentage (\%) \\
\hline active ingredient & 81.6 \\
\hline active ingredient & 16.4 \\
\hline Excipient (glidant, adsorbent) & 1 \\
\hline Excipient (glidant, lubricant) & 1 \\
\hline- & $\mathbf{1 0 0}$ \\
\hline
\end{tabular}

2.10. Extraction and analytical method of sodium benzoate

Sodium benzoate was detected in native form. Twenty five $\mathrm{mg}$ of final blend or capsule filling was extracted with $1.0 \mathrm{ml}$ methanol (60 minutes, $75^{\circ} \mathrm{C}$ ), centrifuged for 1 minute on $13000 \mathrm{RPM}$, and the supernatant was diluted 1600 -fold. One $\mu \mathrm{l}$ of the sample solution was injected into LCESI-MS/MS equipment (Thermo ACCELA $600+$ Thermo LTQ XL), and was studied in water/acetonitrile gradient elution on YMC Triart C18 (100 $\mathrm{mm} \times 3 \mathrm{~mm} \times 1.9 \mu \mathrm{m})$ column. Chromatographic gradient: A: bidestillated water $+0.1 \% \mathrm{HCOOH}$, $\mathrm{B}: \mathrm{MeCN}+0.1 \% \mathrm{NH}_{4} \mathrm{OAc} ; 0$ min: $20 \% \mathrm{~B} ; 1 \mathrm{~min}$ : $20 \%$ B; 10 min: $100 \%$ B; 16 min: $100 \%$; $16.50 \mathrm{~min}$, 20\%; 19 min: $20 \%$. ESI parameters: ion source 175 ${ }^{\circ} \mathrm{C},-5 \mathrm{kV}, 100 \mu \mathrm{A}$; capillar $275{ }^{\circ} \mathrm{C},-8 \mathrm{kV}$; gas flow $15 \mathrm{arb}$, secondary gas flow $5 \mathrm{arb}$. Detection: Isolation width: $1 \mathrm{~m} / \mathrm{z}, 120.5-122.5 \mathrm{~m} / \mathrm{z}$ range. $[\mathrm{M}-\mathrm{H}]^{+}$ ions were measured in SIM mode: sodium benzoate 121.

\subsection{Capsule filling using manual capsule-filling machine.}

Final blend was filled loosely and also tightly with the help of tamper device using a Pro Filler 1100 manual capsule filling equipment into HPMC capsules of size " 0 ".

\subsection{Capsule filling using semi-automatic capsule-filling machine}

Capsules were filled with final blend using CAP8 CAPSUGEL semi-automatic capsule filling machine into size "O" HPMC capsules. The speed of the rotation desk was 1500 RPM, the speed of the retifier was $1500 \mathrm{RPM}$, the vacuum was set at 60 $\mathrm{kPa}$, and the compressor at 90PSI $(\sim 620 \mathrm{kPa})$. In the manufacturing room the temperature was at 21$25^{\circ} \mathrm{C}$, and the relative humidity was $31 \%$. The encapsulation process reached 5000 capsules per hour $(\mathrm{CPH})$ with these parameters. 


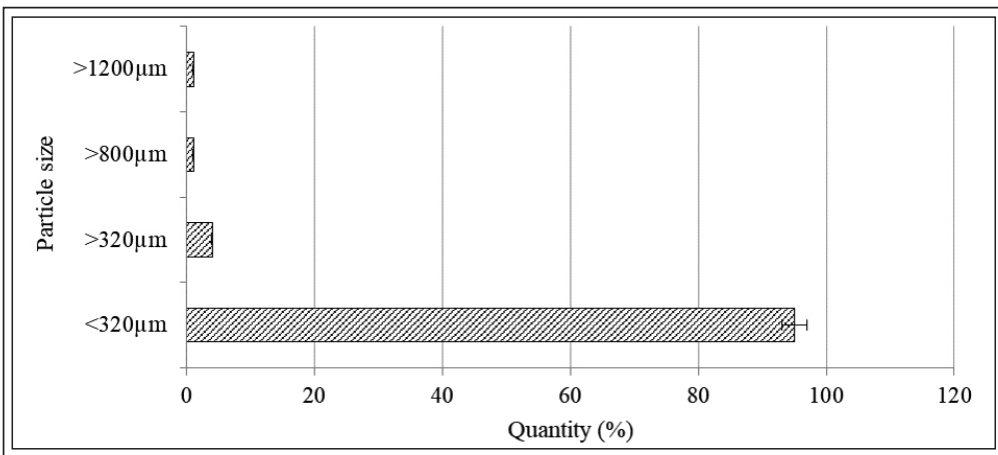

Figure 3 Sieve analysis of ground product

\subsection{Test of the uniformity of mass and the determination of percentage deviation}

Uniformity of mass for capsules were determined according to Ph. Eur. 10 [38]. 20 capsules filled with final blend were selected at random. The capsules were weighed then the contents were removed completely as possible. The emptied capsule shells were weighed. The net weight of fill content was determined by subtracting the weight of the shells from the weight of intact capsule. The average mass of capsules and the percentage deviation was determined.

\subsection{Accelerated stability study of capsules filled with final blend}

Capsules filled with final blend were randomly taken for the stability study from three different manufacturing batches (20 capsules from each batch). Capsules were kept in Memmert HPP constant climate chamber at $30{ }^{\circ} \mathrm{C}$ and $65 \%$ Relative Humidity. The duration of the accelerated stability study was 6 months.

\section{Results}

\subsection{Temperature measurement during the operation of grinding turmeric powder}

Figure 1 presents the values of temperature during the whole process of grinding. The time of grinding process was 15 minutes, the temperature value was maximum $31{ }^{\circ} \mathrm{C}$ which does not influence the quality of turmeric powder.

\subsection{Sieve analysis of ground turmeric powder}

The particle size distribution of ground turmeric is presented in Table IV. $95 \%$ of the turmeric powder passed through the $320 \mu \mathrm{m}$ sieve size, which means that the grinding process resulted in a fine powder. Since less than $1 \%$ of the material retained on the $1.2 \mathrm{~mm}$ and $800 \mu \mathrm{m}$, the particle size distribution was considered proper. The results of the sieve analysis are presented as a mass percent in Figure 3.

\subsection{Rheological properties of ground turmeric powder}

The angle of repose was between $44-50^{\circ}$ which means that the flow property of ground turmeric powder is poor. In order to optimize the powder flowability glidant and lubricant excipients were considered indispensable for further processing.

\subsection{Sieve analysis of the final blend}

The particle size distribution of the final blend can be seen on Table V. $97 \%$ of the powder passed through the $320 \mu \mathrm{m}$ sieve size, which means that the mixing resulted in a fine powder. Since less than $1 \%$ of the material retained on the $1.2 \mathrm{~mm}$ and $800 \mu \mathrm{m}$, the particle size distribution was considered proper. The results of the sieve analysis are shown in Figure 4.

\subsection{Rheological properties of the final blend}

The final blend's angle of repose resulted was between $38-42^{\circ}$. Based on these examinations, the flow properties of the final blend are considered fair, and it does not require aid or excipients for further processing.

\subsection{Homogeneity of the final blend}

The relative standard deviation of curcumin was $19.47 \%$, demethoxycurcumin was $20.99 \%$, bis-

Table IV Sieve analysis of ground turmeric

\begin{tabular}{c|c|c|c|c}
\hline Sieve size & $\begin{array}{c}\text { Mass of powder } \\
\text { passed (mg) }\end{array}$ & $\begin{array}{c}\text { Percent of powder } \\
\text { passed (\%) }\end{array}$ & $\begin{array}{c}\text { Mass of powder } \\
\text { retained (mg) }\end{array}$ & $\begin{array}{c}\text { Percent of pow- } \\
\text { der retained (\%) }\end{array}$ \\
\hline $1.2 \mathrm{~mm}$ & 29962 & $>95$ & 28 & $<1$ \\
\hline $800 \mu \mathrm{m}$ & 29940 & $>95$ & 22 & $<1$ \\
\hline $320 \mu \mathrm{m}$ & 29854 & $>95$ & 86 & $<4$ \\
\hline
\end{tabular}




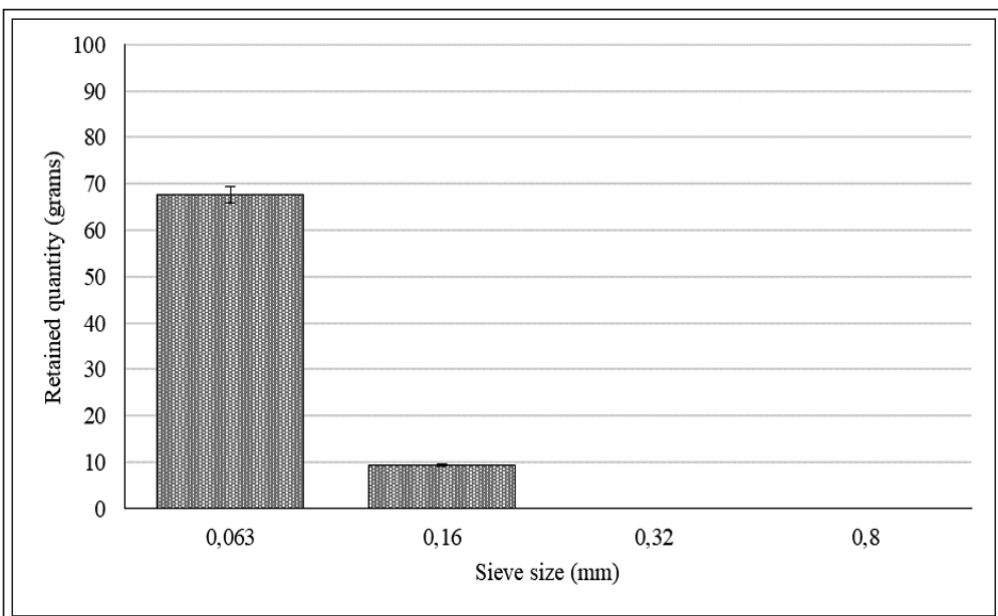

Figure IV Sieve analysis of the final blend

demethoxycurcumin was $20.77 \%$ and benzoate was $16.23 \%$ as shown in Table VI. According to these results, the homogeneity of final blend was sufficient after the mixing process.

\subsection{Result of the uniformity of mass and percentage deviation}

The average mass of fill weight was $389 \mathrm{mg}$ when the capsules were filled loosely while the average mass of fill weight was $490 \mathrm{mg}$ when the capsules were filled and also tampered using manual capsule filler. The average mass of 20 capsules filled with the final blend by semi-automatic capsule filler was $584 \mathrm{mg}$. The percentage deviation of individual capsule mass from the average mass did not exceed $\pm 10 \%$ which means a proper uniformity of mass, according to the European Pharmacopoeia $10^{\text {th }}$ Edition [38].

\subsection{Results of accelerated stability study}

After the 6-month accelerated stability study, the average quantity of the main active components of the formulation was defined via LC-MS analysis and compared to the theoretical initial quantity. According to the results (Table VII) the active ingredients of the final blend (curcumin, demethoxycurcumin, bis-demethoxycurcumin and benzoate) remained stable.

\section{Discussion}

Products containing natural active substances have an increasing role in the treatment of various diseases. The use of the phytotherapeutic Curcuma longa is becoming more and more common in medicine as it contains valuable active substances with proven antioxidant and anti-inflammatory effects $[3,7]$. Curcuminoids, especially curcumin are the active components of the plant turmeric, safe to take orally even in high amounts [39]. Curcumin effectivity has been confirmed on several fields of medical therapy with in vitro, in vivo and clinical studies. Based on the literature it has neuroprotective, memory enhancing, hypoglycemic, anti-tumor, hepatoprotective, and cardioprotective effects [21,22]. Being a natural, herbal remedy, patient compliance may be higher and fewer side effects are expected [40]. The preventive effects of curcumin are in harmony with the modern medicinal principles [41].

According to Maier et al. curcumin combined with sodium benzoate could reduce activity of autoimmune disorders or of cardiovascular and neurodegenerative diseases [42]. Sodium benzoate is the metabolite of cinnamon and the sodium salt of benzoic acid, is also confirmed as safe to take orally, has an antioxidant capacity on its own, but has a combined effect with curcumin in inflammatory conditions. Khasnavis and Pahan reported that sodium benzoate has neuro-pharmacological properties, including relief of panic symptoms, and protection of astrocytes and neurons protein in Parkinson's disease [43].

In the present study, HPMC capsules containing turmeric and sodium benzoate were developed. The HPMC capsule shells have several benefits as they are resistant to gastric juice, therefore protect the active ingredients of the formulation from the damaging effects of low $\mathrm{pH}$ values. In the small intestines the sustained release of the filling is ensured by the HPMC capsules, which is beneficial regarding the bioavailability of the poorly soluble curcumin [44]. The capsule shells assure easy, patient-friendly to take, and compatible with vegan or veg-

Table V Sieve analysis of the final blend

\begin{tabular}{c|c|c|c|c}
\hline Sieve size & $\begin{array}{c}\text { Mass of powder } \\
\text { passed (mg) }\end{array}$ & $\begin{array}{c}\text { Percent of powder } \\
\text { passed (\%) }\end{array}$ & $\begin{array}{c}\text { Mass of powder } \\
\text { retained (mg) }\end{array}$ & $\begin{array}{c}\text { Percent of pow- } \\
\text { der retained (\%) }\end{array}$ \\
\hline $1.2 \mathrm{~mm}$ & 29865 & $>99$ & 134 & $<1$ \\
\hline $800 \mu \mathrm{m}$ & 29609 & $>99$ & 256 & $<1$ \\
\hline $320 \mu \mathrm{m}$ & 29229 & $>97$ & 379 & $<2$ \\
\hline
\end{tabular}


Table VI Homogenity of the final blend after mixing

\begin{tabular}{c|c}
\hline Component & $\begin{array}{c}\text { Relative variance of } \\
\text { quantity }\end{array}$ \\
\hline curcumin & $19.47 \%$ \\
\hline demethoxycurcumin & $20.99 \%$ \\
\hline bis-demethoxycurcumin & $20.77 \%$ \\
\hline benzoate & $16.23 \%$ \\
\hline
\end{tabular}

etarian diet, and religious or ethnic dietary restrictions which forbid the use of animal products [45].

A dietary supplement containing turmeric and sodium benzoate, filled in HPMC capsule shells has been successfully developed. The proper grinding of the herbal drug was crucial for the formulation, which was carried out with the monitoring of the temperature through the whole process, to prevent the damage of the main components.

The particle size distribution of the fine turmeric powder was suitable, however its hygroscopic property made necessary to maintain a constant low relative humidity of the room through the whole manufacturing process.

In order to investigate the flow properties of the filling, sieve analysis and rheological measurements were taken with the ground turmeric and with the final blend. The powder flow plays an important role in the manufacture of dosage form such as capsules and it is often a critical point of the process [36]. Proper powder flow allows uniform particle packing and a constant volume-tomass ratio which maintains capsule weight uniformity and consistent physicomechanical properties of capsule dosage forms [36]. Hardy et al. has also reported that the appropriate flow properties of the final blend are necessary to the production of capsules with a consistent fill weight [46].

According to our examination the rheological properties of the ground turmeric were not sufficient. Therefore, magnesium stearate and anhydrous colloidal silica were also added to the formulation as lubricant and glidant in 1-1\%, respectively. The effect of lubricants on the flowability has been examined by several researchers. Liu et al. found that the addition of $0.5 \mathrm{wt} \%$ of magnesium stearate improved the flowability of cohesive ibuprofen [47].

The great difference between the quantities of components in the composition of the final blend might lead to homogeneity issues; hence the importance of the proper mixing was crucial. We developed a special sample taking method and analyzed the samples of the final blend after mixing, also studied the particle size distribution and the rheological properties of the final blend. All the results confirmed that the final blend was a homogenous powder mix suitable for capsule filling.

A $490 \mathrm{mg}$ capsule filling weight can be achieved with semi-automatic filling process in case of size " 0 " capsule shells. The filling process was monitored by the measurement of the weight uniformity of the capsules and the division of individual capsule weight from the average.

Our results showed that the formulated capsules complied with the requirements of the European Pharmacopoeia [38]. Finally, the product underwent an accelerated stability study, which confirmed that the content of the main active components did not change after stored on $30^{\circ} \mathrm{C}$ and $60 \%$ relative humidity for six months.

\section{Conclusions}

In our present study HPMC capsules containing turmeric powder and sodium benzoate were formulated with magnesium stearate and anhydrous colloidal silica in order to improve flow properties of the powder. According to our examinations the formulation may go to further in vivo experiments.

\section{Funding}

GINOP-2.1.7-15-2016-01492 grant entitled "Insulin érzékenyítő és memória javító hatású curcuma kapszula és kapcsolódó biomarker kifejlesztése".

The research was supported by the Thematic Excellence Programme (TKP2020-IKA-04) of the Ministry for Innovation and Technology in Hungary.

\section{Conflict of interest}

The authors declare no conflict of interest.

Table VII Active component quantity after accelerated stability study

\begin{tabular}{c|c}
\hline Component & Average quantity compared to theoretical initial \\
\hline curcumin & $111.4 \%$ \\
\hline demethoxycurcumin & $112.3 \%$ \\
\hline bis-demethoxycurcumin & $92.5 \%$ \\
\hline benzoate & $83.68 \%$ \\
\hline
\end{tabular}




\section{References}

1. Szőke, É.; Balázs, A.; Blázovics, A.; Kéry, Á.; Kursinszki, L.; Lemberkovics, É.; Then, M.; Alberti-Dér, Á.; et al. Gyógynövény és Drogismeret Farmakognózia - Fitokémia, gyógynövények alkalmazása. Semmelweis Egyetem, Egyetemi jegyzet, 2012.

2. Dosoky, N.S.; Setzer, W.N. Chemical Composition and Biological Activities of Essential Oils of Curcuma Species. Nutrients. 2018, 10(9), 1196. https://doi. org/10.3390/nu10091196

3. Hewlings, S.J.; Kalman, D.S. Curcumin: A Review of Its Effects on Human Health. Foods (Basel, Switzerland) 2017, 6. https://doi.org/10.3390/foods6100092

4. Labban, L. Medicinal and pharmacological properties of Turmeric (Curcuma longa): A review. Int J Pharm Biomed Sci. 2014, 5, 17-23.

5. Nelson, K.M.; Dahlin, J.L.; Bisson, J.; Graham, J.; Pauli, G.F.; Walters, M.A. The Essential Medicinal Chemistry of Curcumin. J. Med. Chem. 2017, 60, 1620-1637. https://doi.org/10.1021/acs.jmedchem.6b00975

6. Dosoky, N.S.; Satyal, P.; Setzer, W.N. Variations in the Volatile Compositions of Curcuma Species. Foods. 2019, 8(2), 53. https://doi.org/10.3390/ foods 8020053

7. Menon, V.P.; Sudheer, A.R. Antioxidant and antiinflammatory properties of curcumin. Adv Exp Med Biol. 2007, 595, 105-25. https://doi.org/10.1007/978-0387-46401-5_3

8. Joshi, P.; Jain, S.; Sharma, V. Turmeric (Curcuma longa) a natural source of edible yellow colour. Int. J. Food Sci. Technol. 2009, 44, 2402-2406. https://doi. org/10.1111/j.1365-2621.2009.01914.x

9. Noorafshan, A.; Ashkani Esfahani, S. A Review of Therapeutic Effects of Curcumin. Curr. Pharm. Des. 2012, 19. https://doi.org/10.2174/138161213805289273

10. Panahi, Y.; Fazlolahzadeh, O.; Atkin, S.; Majeed, M.; Butler, A.; Johnston, T.; Sahebkar, A. Evidence of curcumin and curcumin analogue effects in skin diseases: A narrative review. J. Cell. Physiol. 2018, 234. https://doi.org/10.1002/jcp.27096

11. Sharifi-Rad, J.; Rayess, Y. El; Rizk, A.A.; Sadaka, C.; Zgheib, R.; Zam, W.; Sestito, S.; Rapposelli, S.; NeffeSkocińska, K.; Zielińska, D.; et al. Turmeric and Its Major Compound Curcumin on Health: Bioactive Effects and Safety Profiles for Food, Pharmaceutical, Biotechnological and Medicinal Applications. Front. Pharmacol. 2020, 11, 1021. https://doi.org/10.3389/fphar.2020.01021

12. Fadus, M.C.; Lau, C.; Bikhchandani, J.; Lynch, H.T. Curcumin: An age-old anti-inflammatory and anti-neoplastic agent. J. Tradit. Complement. Med. 2017, 7, 339-346. https://doi.org/10.1016/j.jtcme.2016.08.002

13. Ghorbani, Z.; Hekmatdoost, A.; Mirmiran P. Antihyperglycemic and insulin sensitizer effects of turmeric and its principle constituent curcumin. Int J Endocrinol Metab. 2014, 12(4), e18081. https://doi. org/10.5812/ijem.18081

14. Gupta, S.C.; Patchva, S.; Aggarwal, B.B. Therapeutic roles of curcumin: lessons learned from clini- cal trials. AAPS J. 2013, 15(1), 195-218. https://doi. org/10.1208/s12248-012-9432-8

15. Farooqui, A.A.; Farooqui, T.; Madan, A.; Ong, J.H.; Ong, W.Y. Ayurvedic Medicine for the Treatment of Dementia: Mechanistic Aspects. Evid Based Complement Alternat Med. 2018, 2018, 2481076. https:// doi.org/10.1155/2018/2481076

16. Bhupathyraaj, M.; Mullaicharam, A.R.; Maheswaran, A. Pharmacological effects of Curcumin. Int J Nutr Pharmacol Neurol Dis 2012, 2, 92-9(2). https://doi.org/10.4103/2231-0738.95930

17. Lee, S.-Y.; Cho, S.-S.; Li, Y.; Bae, C.-S.; Park, K.M.; Park, D.-H. Anti-inflammatory Effect of Curcuma longa and Allium hookeri Co-treatment via NF- $\kappa \mathrm{B}$ and COX-2 Pathways. Sci. Rep. 2020, 10, 5718. https://doi.org/10.1038/s41598-020-62749-7

18. Vollono, L.; Falconi, M.; Gaziano, R.; Iacovelli, F.; Dika, E.; Terracciano, C.; Bianchi, L.; Campione, E. Potential of Curcumin in Skin Disorders. Nutrients. 2019, 11(9), 2169 https://doi.org/10.3390/nu11092169

19. Jacob, A.; Wu, R.; Zhou, M.; Wang, P. Mechanism of the Anti-inflammatory Effect of Curcumin: PPARgamma Activation. PPAR Res. 2007, 2007, 89369. https://doi.org/10.1155/2007/89369

20. Deogade, S; Ghate, S. Curcumin: Therapeutic applications in systemic and oral health. Int. J. Biol. Pharm. Res. 2015, 6(4), 281-290.

21. Vaughn, A.; Branum, A.; Sivamani, R. Effects of Turmeric ( Curcuma longa ) on Skin Health: A Systematic Review of the Clinical Evidence: Effects of Curcuma longa on Skin Health. Phyther. Res. 2016, 30. https://doi.org/10.1002/ptr.5640

22. Qin, S.; Huang, L.; Gong, J.; Shen, S.; Huang, J.; Ren, $\mathrm{H}$.; Hu, H. Efficacy and safety of turmeric and curcumin in lowering blood lipid levels in patients with cardiovascular risk factors: a meta-analysis of randomized controlled trials. Nutr. J. 2017, 16, 68. https:// doi.org/10.1186/s12937-017-0293-y

23. Cianfruglia, L.; Minnelli, C.; Laudadio, E.; Scirè, A.; Armeni, T. Side Effects of Curcumin: Epigenetic and Antiproliferative Implications for Normal Dermal Fibroblast and Breast Cancer Cells. Antioxidants 2019, 8, 382. https://doi.org/10.3390/ antiox8090382

24. Hassanzadeh, K.; Buccarello, L.; Dragotto, J.; Mohammadi, A.; Corbo, M.; Feligioni, M. Obstacles against the marketing of curcumin as a drug. Int. J. Mol. Sci. 2020, 21, 1-35. https://doi.org/10.3390/ ijms21186619

25. Filardi, T.; Varì, R.; Ferretti, E.; Zicari, A.; Morano, S.; Santangelo, C. Curcumin: Could This Compound Be Useful in Pregnancy and Pregnancy-Related Complications? Nutrients 2020, 12, 3179. https://doi. org/10.3390/nu12103179

26. Van den Berghe-Snorek, S.; Stankovich, M.T. Thermodynamic control of D-amino acid oxidase by benzoate binding. J. Biol. Chem. 1985, 260, 33733379. https://doi.org/10.1016/S0021-9258(19)83631-1

27. Schnedl, W.J.; Schenk, M.; Lackner, S.; Enko, D.; Man- 
gge, H.; Forster, F. Diamine oxidase supplementation improves symptoms in patients with histamine intolerance. Food Sci. Biotechnol. 2019, 28, 1779-1784. https://doi.org/10.1007/s10068-019-00627-3

28. Madeira, C.; Freitas, M.E.; Vargas-Lopes, C.; Wolosker, H.; Panizzutti, R. Increased brain d-amino acid oxidase (DAAO) activity in schizophrenia. Schizophr. Res. 2008, 101, 76-83. https://doi.org/10.1016/j. schres.2008.02.002

29. Modi, K.K.; Roy, A.; Brahmachari, S.; Rangasamy, S.B.; Pahan, K. Cinnamon and Its Metabolite Sodium Benzoate Attenuate the Activation of p21rac and Protect Memory and Learning in an Animal Model of Alzheimer's Disease. PLoS One 2015, 10, e0130398. https://doi.org/10.1371/journal.pone.0130398

30. Song, W.-B.; Wang, Y.-Y.; Meng, F.-S.; Zhang, Q.H.; Zeng, J.-Y.; Xiao, L.-P.; Yu, X.-P.; Peng, D.; Su, L.; Xiao, B.; et al. Curcumin protects intestinal mucosal barrier function of rat enteritis via activation of MKP-1 and attenuation of $\mathrm{p} 38$ and NF- $\mathrm{kB}$ activation. PLoS One 2010, 5, e12969. https://doi.org/10.1371/ journal.pone.0012969

31. Maier, E.; Kurz, K.; Jenny, M.; Schennach, H.; Ueberall, F.; Fuchs, D. Food preservatives sodium benzoate and propionic acid and colorant curcumin suppress Th1-type immune response in vitro. Food Chem. Toxicol. 2010, 48, 1950-1956. https://doi. org/10.1016/j.fct.2010.04.042

32. Tran, D.T.; Majerová, D.; Veselý, M.; Kulaviak, L.; Ruzicka, M.C.; Zámostný, P. On the mechanism of colloidal silica action to improve flow properties of pharmaceutical excipients. Int. J. Pharm. 2019, 556, 383-394 https://doi.org/10.1016/j.ijpharm.2018.11.066

33. Jung, H.; Lee, Y.J.; Yoon, W.B. Effect of moisture content on the grinding process and powder properties in food: A review. Processes. 2018, 6, 69. https://doi. org/10.3390/pr6060069

34. Allen, T. Particle size analysis by sieving. In Powder Sampling and Particle Size Determination; Elsevier, 2003; pp. 208-250. https://doi.org/10.1016/B978044451564-3/50006-1

35. Hungarian Pharmacopoeia 8th edition, National Institute of Pharmacy and Nutrition, Hungary, Budapest, 2006.

36. Parezanović, G.Š.; Lalić-Popović, M.; GoločorbinKon, S.; Todorović, N.; Pavlović, N.; Jovičić-Bata, J. The effect of magnesium stearate and sodium starch glycolate on powder flowability. Acta Period. Technol. 2019, 50, 304-310. https://doi.org/10.2298/ APT1950304S
37. Riley, G. S.; Mann, S.; Jesse, R.O. Angle of repose of cohesive powders. J. Powder \& Bulk Sol. Technol. 1978, 2(4), 15-18.

38. European Pharmacopoeia 10th edition, Counsil of Europe, Strasbourg, 2019

39. Aggarwal, B.B., Surh, Y.-J., Shishodia, S. The Molecular Targets and Therapeutic Uses of Curcumin in Health and Disease. Springer US: Boston, MA, 2007; pp. 471-480. https://doi.org/10.1007/978-0-38746401-5

40. Jin, J.; Sklar, G.E.; Min Sen Oh, V.; Chuen Li, S. Factors affecting therapeutic compliance: A review from the patient's perspective. Ther. Clin. Risk Manag. 2008, 4, 269-286. https://doi.org/10.2147/TCRM. S1458

41. Singh, A.R. Modern Medicine: Towards Prevention, Cure, Well-being and Longevity. Mens Sana Monogr. 2010, 8, 17-29. https://doi.org/10.4103/09731229.58817

42. Maier, E.; Kurz, K.; Jenny, M.; Schennach, H.; Ueberall, F.; Fuchs, D. Food preservatives sodium benzoate and propionic acid and colorant curcumin suppress Th1-type immune response in vitro. Food Chem. Toxicol. 2010, 48(7), 1950-1956. https://doi. org/10.1016/j.fct.2010.04.042

43. Khasnavis, S.; Pahan, K. Sodium benzoate, a metabolite of cinnamon and a food additive, upregulates neuroprotective Parkinson disease protein DJ-1 in astrocytes and neurons. J Neuroimmune Pharmacol. 2012, 7(2), 424-435. https://doi.org/10.1007/ s11481-011-9286-3

44. Lopresti, A.L. The Problem of Curcumin and Its Bioavailability: Could Its Gastrointestinal Influence Contribute to Its Overall Health-Enhancing Effects? Adv. Nutr. 2018, 9, 41-50. https://doi.org/10.1093/ advances/nmx011

45. Majee, S.; Majee; Avlani, D.; Gopa, R.; Roy Biswas, G. HPMC AS CAPSULE SHELL MATERIAL: PHYSICOCHEMICAL, PHARMACEUTICAL AND BIOPHARMACEUTICAL PROPERTIES. Int. J. Pharm. Pharm. Sci. 2017, 9. https://doi.org/10.22159/ ijpps.2017v9i10.20707

46. Hardy, I.J.; Fitzpatrick, S.; Booth, S.W. Rational design of powder formulations for tamp filling processes. J. Pharm. Pharmacol. 2003, 55, 1593-1599. https://doi.org/10.1211/0022357022610

47. Liu LX, Marziano I, Bentham AC, Litster JD, White ET, Howes T. Effect of particle properties on the flowability of ibuprofen powders. Int J Pharm. 2008; 362(1-2), 109-17. https://doi.org/10.1016/j.ijpharm.2008.06.023 